\title{
EXPANSÃO DA IGREJA NO BRASIL INDEPENDENTE $(*)$.
}

\author{
Pe. HÉLIO ABRANCHES VIOTTI SJ. \\ do Instituto Histórico e Geográfico de São Paulo.
}

A vinda para o Brasil da Família Real Portuguesa, tangida pela invasão napoleônica, veio propiciar, como sabemos, verdadeira transformação para o vasto domínio de Portugal na América. Principia então o Brasil a emergir de seus status colonial - isto é, de região passivamente submetida à ação de um poder político exterior, ação de um Estado teoricamente desenvolvido sobre região inculta ou em desenvolvimento - para ombrear com o velho reino. Não digo já em matéria econômica, em que largamente o superava, mas quanto às instituições políticas, militares e culturais.

$\mathrm{E}$ foi, como à sociedade se vem repetindo, a atitude perfeitamente estulta das Cortes de Lisboa, empenhadas em espoliar-nos de todas as vantagens adquiridas nesse período, rompendo assim as condições já solenemente estipuladas de nossos liames com a Metrópole, que obrigou as forças vivas aqui despertadas através de uma longa preparação histórica, à "denúncia do pacto social" (1). Sob êste aspecto, a independência nacional brasileira foi o que havia de mais legítimo perante a Moral e o Direito. A ruptura comeou do Iado de lá...

Tratando-se de uma sociedade distinta da sociedade civil, a Igreja em Portugal e suas conquistas, em virtude mesmo de sua organização de carater universalístico - isto significa o nome de Católica! embora em íntima e leal convivência com o Estado Português desde as origens cristãs da nacionalidade, já não dependia entre nós, para sua vida e atividades próprias, da hierarquia estabelecida em Portugal. Dependia, isto sim, tanto aqui como na Metrópole, do arbítrio da

(*). - Palestra pronunciada na Sociedade de Estudos Históricos, em 12 de dezembro de 1972. (Nota da Redação).

(1). - E. Vilhena de Moraes, O patriotismo e o clero no Brasil, Rio de Janeiro, 1929, pp. 30-31. 
Coroa, que se prevalecia dos poderes a ela concedidos pela Sé Apostólica, mediante o padroado outorgado a princípio ao Grão Mestre da Ordem de Cristo.

Se os abusos nessa matéria de invasão do poder civil na esfera do poder eclesiástico eram antigos, a usurpação se converteu em sistema sob o fatal ministério do Marquês de Pombal. Nesse sentido, escreve o antigo núncio em Portugal, Cardeal Bartolomeu Pacca:

"Fez imprimir obras conformes aos seus princípios por escritores aduladores e venais e especialmente o famigerado oratoriano Antônio Pereira. (...) Nelas com perfídia jansenística, se pôs a exaltar a autoridade episcopal, no intuito de deprimir o primado pontifício, e ampliou e estendeu de tal forma a autoridade dos monarcas nas matérias eclesiásticas, que a sua doutrina pouco se afastava do sistema da Igreja Anglicana protestante" (2).

Cooperando entusiasticamente no movimento da Independência, teria podido então a Igreja no Brasil, se outras fossem as condições de sua vitalidade doutrinária e disciplinar, tão deterioradas nessa época pela ação de Pombal e seus epígonos, desvencilhar-se das pesadas cadeias, que lhe havia imposto o Estado, a pretexto de protegê-la. No momento se encontrava ela tremendamente combalida: a expulsão dos jesuitas, com a sumária extinção de seus muitos colégios e seminários, a decadência acelerada das antigas ordens religiosas, desde que em 1764 haviam sido fechados os seus noviciados, o desvirtuamento introduzido na formação dos sacerdotes pelas perniciosas doutrinas, cujo foco principal era agora a "reformada" Universidade de Coimbra, frustraram totalmente essa esperança.

Desde 1745 aliás, data em que Bento XIV criara os bispados de São Paulo e da Mariana, e juntamente as prelazias de Goiaz e Mato Grosso, até 1826, nenhuma alteração havia sofrido a jerarquia eclesiástica no Brasil ou no Pará-Maranhão. Desapareciam os "regulares". Quanto ao clero secular, apesar da atração que exercia naqueles tempos a carreira clerical, se não regredira, estacionara ao menos. Mas de que maneira? Entre 1775 e 1780, foram ordenados em São Paulo por Dom Manuel da Ressurreição nada menos que duzentos e oitenta candidatos da Diocese de Mariana (3)!

Mariana atravessava, após a morte de seu primeiro e grande antístite Dom Manuel da Cruz em 1764, tempos difíceis, quer por vacân-

(2). - Notizie sul Portogallo, 1835, pp. 13-14.

(3). - "Docs. sobre São Paulo no Arquivo Histórico Ultramarino", RIHGB (Tomos especiais, 1956-59), t. VIII, 155-158. V. $n^{\circ} 3.117$, defesa dó bispo de São Paulo. 
cia da diocese, quer por ausência dos bispos seus sucessores, que não sairam de Lisboa. E bem possível que seus procuradores, homens sem visão espiritual e sem autoridade muitas vezes, escancarando assim as portas do sacerdócio a essa turbamulta de indivíduos em maioria despreparados, acreditassem estar opondo à política do governo uma resistência até certo ponto válida. Erro catastrófico! Se relativamente ao aumento da população diminuia o clero, havia ainda outro aspecto muito pior: perdera em grande parte o espírito de sua consagração religiosa...

A "Revolução de Padres" de 1817 em. Pernambuco dá bem a medida de como esse clero, ali formado quase todo em Olinda, no famoso seminário fundado no ano de 1800 pelo sábio Dom José Joaquim da Cunha de Azeredo Coutinho, se deixara infeccionar por ideais puramente terrenos, bafejados pelo liberalismo enciclopedista, pelo jansenismo galicano, enfim pelos miasmas das perniciosas doutrinas, a que Pombal franqueara de par em par as fronteiras do Reino, cada vez mais segregado da influência da Santa Sé. Contra o avanço generalizado da indisciplina, no campo das idéias e dos costumes, pouco puderam fazer alguns dos zelosos pastores nomeados por D. Maria I ou pelo príncipe regente, como em Mariana, por exemplo, Dom Frei Domingos da Encarnação Pontével (1779-1793) e Dom Frei Cipriano de São José (1798-1817) .

Por ocasião da Independência, Olinda e as Prelazias de Goiaz e Mato Grosso se achavam vacantes. Excetuado o bispo do Pará, Dom Romualdo de Sousa Coelho (que, apesar de brasileiro, contemporizou a princípio com a causa da Metrópole), os demais prelados eram portugueses. O Arcebispo da Bahia Dom Frei Vicente da Soledade e Castro, apanhado pelos acontecimentos em Lisboa, lá se deixou ficar... O bispo do Maranhão Dom Frei Joaquim de Nossa Senhora de Nazaré, resistindo ao instante apelo de Dom Pedro I preferiu retirar-se para Portugal. Os restantes, porém, Dom Frei José da Santíssima Trindade, de Mariana, Dom José Caetano da Silva Coutinho, do Rio de Janeiro, e Dom Mateus de Abreu Pereira, de São Paulo, abraçaram lealmente a causa do Brasil. O bispo de São Paulo e seu clero tiveram no movimento emancipador a mais destacada atuação.

$\mathrm{Na}$ representação brasileira às Cortes de Lisboa tomaram parte dezoito eclesiásticos, entre os quais se salientou Dom Azeredo Coutinho, então bispo de Elvas, e o Padre Diogo Antônio Feijó. Para a Assembléia Constituinte do Império contou igualmente o clero com numerosa representação, em que se leem nomes de sacerdotes da Revolução de 1817, e de vários deputados das Cortes. Presidia a Assembléia o Bispo do Rio de Janeiro. Não foram os clérigos, entretanto, os 
que nela defenderam a doutrina ortodoxa em matérias político-religiosas, e sim um grupo de leigos, a cuja frente se destacou José Maria da Silva Lisboa, futuro Visconde de Cairú, homem de vastíssimos conhecimentos e notável orador. Um único sacerdote houve, que se juntou a esse grupo, o antigo inconfidente Pe. Manuel Rodrigues da Costa (4).

Enviado extraordinário do Novo Império à Santa Sé, foi um sacerdote, Monsenhor Francisco Correia Vidigal. O teor das instruções que levava, mais parecia um insulto e um desafio irrogados pelo regalismo pombalino à face da Cúria Romana. Deixando-as de lado, logrou Vidigal chegar à presença de Leão XII, de quem obteve, após o reconhecimento de nossa Independência, a criação da nunciatura (rebaixada mais tarde a simples legação), a manutenção da Ordem de Cristo e a confirmação de seus privilégios de caráter político-religioso. Continuava assim no Brasil o padroado, instrumento durante os primeiros séculos a serviço da dilatação da Fé nas conquistas portuguesas, mas, desde o século XVIII pelo menos, fonte para a Igreja da mais vexatória opressão.

Com a Abdicação e a Regência sobe à ribalta do cenário político com o máximo destaque a controvertida figura de Diogo Antônio Feijó. Não lhe faltava sem dúvida uma grande firmeza de caráter, que o preservou pessoalmente de certas consequências de suas extraviadas doutrinas canônicas e teológicas, imbuido como estava da pior forma do regalismo pombalino, eivado, para mais, de tendências jansenísticas. Ministro da Justiça, em circular de 9 de dezembro de 1831, lembrava ele ao presidente da Província de Minas a proibição dos noviciados de 1764 . Visava com isso obter o fechamento do noviciado dos lazaristas no Caraça, expressamente autorizado onze anos antes por Dom João VI. A lei posterior de Tomás Nabuco de Araujo, de 19 de maio de 1855, nada inovou, como estamos vendo.

Mas foi, como deputado e depois como regente único do Império, que se colocou Feijó em maior evidência, em sua atitude agressiva contra a Igreja, que o amparara na infância, lhe dera toda a formação que possuia e, em grande parte, a sua projeção política. Como deputado foi adversário empedernido do celibato clerical. Como regente chegou a ameaçar com o cisma a Igreja no Brasil, pretendendo assim contornar a recusa da Santa Sé à confirmação de seu companheiro de ideais, Pe. Antônio Maria de Moura, apresentado como bispo do Rio de Janeiro. Nunca a Igreja Católica no Brasil correu maior risco do

(4) . - E. Vilhena de Moraes, O patriotismo e o clero no Brasil, Rio de Janeiro, 1929, pp. 37-48. 
que quando um de seus sacerdotes, fruto póstumo do antirromanismo pombalesco, ocupou a suprema curul no governo do país!

Para enfrentá-lo, todavia, não faltou um notável representante do clero brasileiro, o Arcebispo da Bahia, Dom Romualdo Antônio de Seixas, nascido no Pará. Oralmente, como deputado, mais de uma vez. E também como fecundo escritor. Às Obras completas do Marquês de Santa Cruz, cumpre juntar ainda suas Memórias, indispensáveis para a história da Igreja no longo período de seu pontificado de trinta e dois anos. Embora participante de inveterados preconceitos contra os jesuitas, foi naquelas circunstâncias o paladino da ortodoxia e um zeloso pastor de almas.

Como ele, poderíamos citar os nomes de muitos outros bispos, que nessa época de decadência religiosa souberam, graças a uma atuação sobrenaturalmente fecunda, preparar para a Igreja tempos mais felizes no futuro. Lembrarei apenas três: Dom João da Purificação Marques Perdigão em Pernambuco (1831-1864), Dom Antônio Joaquim de Melo em São Paulo (1857-1861) e sobretudo Dom Antônio Ferreira Viçoso em Mariana 1844-1875). Lazarista português, chegado ao Brasil, sob o reinado de Dom João VI, foi um dos fundadores do famoso Colégio do Caraça, no ano de 1820 . Sua santidade e zelo apostólico ficarão para sempre exarados na clássica biografia redigida por um de seus sucessores, Dom Silvério Gomes Pimenta.

Menos afetado pelo ódio ao monaquismo, senão positivamente favorável a ele, patrocinou Dom João VI a Congregação da Missão no Brasil. Aqui teve ela atuação verdadeiramente providencial. Com suas missões populares, e a direção de seminários, a começar pelo de Mariana, concorreram os lazaristas durante mais de um século de modo eficacíssimo para a restauração da vida cristã em nossa pátria. Suprindo igualmente as atividades apostólicas das antigas Ordens religiosas, condenadas à extinção gradativa, (aguardando o governo de olho vivo o momento de empolgar os bens de mão morta), distinguiram-se desde o século XVIII os capuchinhos italianos, seja em missões com indígenas, seja na pregação popular.

Após uma primeira tentativa de se estabelecer no Brasil em 1842, reiniciaram aqui definitivamente os jesuitas o seu apostolado. No ano de 1865 fundavam no Recife o Colégio de São Francisco Xavier e se estabeleciam em Itú, onde só dois anos depois lograram abrir o Colégio São Luis. De Itú irradiaram suas atividades por muitos outros lugares. Em 1886 surgia o Colégio Anchieta em Nova Friburgo. Em 1903 o Colégio Santo Inácio no Rio de Janeiro. Jesuitas alemães, vindos contemporâneamente a cuidar das colônias alemãs do Rio Grande do Sul, fundaram em São Leopoldo o Ginásio de Nossa Senhora da 
Conceição. Ai se abrigou depois por muitos anos o grande Seminário, donde saiu o numeroso e modelar clero riograndense até pouco anos atrás. O colégio do Recife teve de cerrar suas portas diante da violência, durante a chamada "Questão religiosa".

Para a evolução da história religiosa do país o "conflito epíscopo maçônico" de 1872-1875 pode ser considerado um verdadeiro divortium acquarum. Durante ele foram levados pelo governo às últimas consequências os mesmos princípios do regalismo pombalino, agravados sem dúvida pelas idéias do Iluminismo enciclopedista, tão bem promovidos aqui como alhures pela Franco-maçonaria. Publicamos há nove anos atrás em tradução portuguesa uma carta de Pio IX, de 14 de julho de 1873, ao presidente e vereadores da Câmara de Taubaté, em que o Sumo Pontífice aponta essa sociedade secreta, como origem da guerra então desencadeada em quase todo o mundo contra a Igreja (5).

São conhecidos os episódios da "Questão religiosa". Discurso do orador oficial da maçonaria, Padre Almeida Martins, na homenagem prestada a 3 de março de 1872 ao Visconde do Rio Branco pela Lei do "ventre livre". Sua suspensão a divinis pelo Bispo do Rio de Janeiro Dom Pedro Maria de Lacerda. Posse de Dom Vital Maria Gonçalves de Oliveira, a 24 de maio desse mesmo ano como bispo de Olinda. Breve Quamquam dolores de Pio IX aprovando atos de Dom Vital na feroz campanha movida por maçons, aninhados nas irmandades católicas, contra a Igreja. Aviso do Ministro do Império de 27 de setembro de 1873, convidando o procurador da Coroa a promover acusação contra o bispo, que se recusara a levantar o interdito lançado sobre a Irmandade do Santíssimo Sacramento do Recife. Prisão de Dom Vital a 2 de janeiro de 1874 e sua condenação a 21 de fevereiro pelo Supremo Tribunal de Justiça a quatro anos de prisão com trabalhos e custas.

Por idênticas razões era em seguida preso em Belém o bispo do Pará, Dom Antônio de Macedo Costa, que se viu condenado a 1 de julho de 1874 à mesma pena aplicada ao, de Pernambuco. Tais punições, realmente espantosas, foram comutadas pelo Imperador para quatro anos de prisão simples em qualquer das fortalezas do Rio de Janeirò. Na de São João fora recolhido Dom Vital. Dom Macedo Costa o foi na da Ilha das Cobras. Devendo o monarca ausentar-se pela segunda vez em viagem no ano seguinte, convidou para chefe do gabinete ao Duque de Caxias. Condicionou este a aceitação do honroso encargo à prévia anistia dos bispos. Cedeu o Imperador a contragosto . E a 17 de setembro de 1875 eram anistiados Dom Vital e Dom Macedo Costa.

(5). - Revista Eclesiástica Brasileira, XXIII, fascículo 3, (setembro de 1963), pp. 663-664. 
Como não podia deixar de ser, tiveram tais sucessos profunda repercussão na consciência religiosa do país. Brilhou mais uma vez nessa oportunidade a ilustração religiosa e o desassombro cristão de um pugilo de leigos. Nem faltou o clero em manifestar sua solidariedade aos perseguidos.

"Se houve um Almeida Martins e um Saldanha Marinho escreve o historiador Eugênio Vilhena de Moraes - houve também um Leandro Bezerra, um Tarquínio de Sousa, um Figueira de Melo, um Manuel dos Reis, um Diogo de Vasconcelos, um Ferreira Viana, um Cândido Mendes e um Zacarias de Gois" (6).

Mas essa heroica atitude dos bispos transcendeu as próprias fronteiras do país. Representou para a consciência católica do mundo

"a reação da Igreja Brasileira contra as usurpações sacrílegas do cesarismo" (7).

Através de humilhante holocausto, a exemplo do Calvário, alvorejou então para a Igreja no Brasil a certeza vitoriosa da libertação.

Com a obstinada conduta do Imperador, ditada pelos seus preconceitos liberais sobretudo, sacrificando para satisfação da sociedade secreta condenada pela Igreja dois dos mais eminentes membros da jerarquia sagrada em nossa terra, alienara sem dúvida a monarquia boa parte de sua popularidade entre os católicos brasileiros. Se não se pode considerar como fator positivo para a queda do Império, criou sem dúvida a "Questão religiosa" uma condição favorável a mais para isso. Se não quisermos apelar para "a justiça de Deus na voz da História"...

As causas que temos visto em ação contra a vitalidade do Catolicismo no Brasil, continuaram, no segundo reinado, a influir na estagnação da Igreja entre nós. Chegamos assim ao final do período monárquico, com apenas doze dioceses. Em 1826 eram elevadas a bispados as duas prelazias de Goiaz e Mato Grosso. Em 1848 era criada a Diocese de São Pedro, com sede em Porto Alegre. Em 1854, a do Ceará, com sede em Fortaleza, e a de Diamantina em Minas Gerais. Doze dioceses apenas... E o que impressiona ainda mais: em todas elas apenas setecentos padres! De três mil, que existiam no país no terceiro quartel do século XVIII, estavam reduzidos a menos de um terço... E o Brasil crescera, contando cerca de 12 milhões de habitantes (8). p. 14 .

(6). - Op. cit., p. 77 .

(7). - D. F. de Aquino Correa, Bispos do Brasil, Rio de Janeiro, 1939,

(8) . - Lacroix S. C. J., Pascoal, O mais urgente problema do Brasil, Petrópolis, 1936, p. 88 e 92. 
Esplêndidas sementes, entretanto, haviam sido lançadas no solo fertil da religiosidade brasileira para reavivar no Brasil a seara divina. Lembremos duas apenas: Em 1871 fundava em Itú o Pe. Bartolomeu Taddei a pia associação do Apostolado da Oração. Espalhando-se rapidamente pelo território nacional, reacendeu nas paróquias, onde o jansenismo esterelizara a prática da vida cristã, a vida sacramental. Nas manifestações externas do culto se cifrava então em grande parte a nossa religiosidade. Em 1872, há um século precisamente, surgia no Rio de Janeiro a primeira Conferência de São Vicente de Paulo, que hoje congrega no Brasil cem mil aderentes, dedicados à prática da caridade oculta tão recomendada no Evangelho.

Não poderíamos esquecer os salesianos, chegados a Niteroi no ano de 1883. Falar nos Filhos de São João Bosco é relembrar a restauração nos tempos atuais da epopéia missionária, em que se haviam assinalado outrora, no Brasil e na Amazônia, jesuitas, franciscanos, carmelitas, mercedários e, posteriormente, em menor escala os capuchinhos. Sua rede de estabelecimentos de ensino, ainda hoje estendida de Norte a Sul no país, vem contribuindo, para a recristianização do elemento masculino entre nós. Tampouco devemos omitir o papel desempenhado, desde a primeira metade do século XVIII, pelas Irmãs de Caridade, trazidas para Mariana por Dom Viçoso, acompanhando aos lazaristas franceses.

Daquelas duas "colunas de Hércules", que haviam fixado no dizer de Dom Aquino Correa os "limites do regalismo: non plus ultra!", sobreviveu ainda até os inícios da história da República o bispo do Pará, promovido em junho de 1890 a arcebispo da Bahia e primaz do Brasil. Com o período republicano surgia o agnosticismo laicista. Mau grado seu, entretanto, batizada embora pelo "culto da humanidade" e controlada durante tanto tempo pelos ocultos manejos da maçonaria, já não logrou nossa Primeira República impedir a expansão da Igreja, libertada finalmente de suas antigas cadeias.

"Dom Antônio de Macedo Costa exercia então - escreve o Dr. Francisco Badaró - um primado absoluto na Igreja do Brasil, que emanava do talento e do martírio" (9).

Empenhou-se vivamente. à testa do episcopado, em conjurar os males que se poderiam temer em detrimento dos direitos da religião. Foi assim que à Pastoral Coletiva de 19 de março de 1890, extraordinário documento de coragem e de sabedoria, se seguiram duas Reclamações dirigidas uma ao Chefe do Governo Provisório, outra ao Con-

(9). - F. de M. Costa, Lutas e Vitórias, Bahia, 1916, p. 12. 
gresso Constituinte Nacional. Comentava a pastoral o decreto de 7 de janeiro, com que estabelecia o governo a separação entre a Igreja e o Estado.

"Não tratemos mais da ferida que foi feita à Igreja em nosso país" - exclamam a certa altura os bispos. "Tinha ela duplo direito, à proteção e à liberdade. Tiraram-lhe a primeira. Não cooperamos para isso. Infelizmente, porém, é um fato: o Brasil não é mais uma potência católica". "Que fazer neste caso concreto...?" $\mathrm{E}$ respondiam:... 1) ... "apreciar a liberdade..., tal como nos é reconhecida...;2) . . fazer votos para que ela se complete e se torne efetiva; 3 ) cumprir... nosso deveres cristãos na nova era que se inaugura para o Cristianismo Católico no nosso caro Brasil" (10).

E com esse programa realista, entrou a Igreja a expandir-se livre e decididamente. As restrições aos direitos da Igreja, que permaneciam nos textos legais, foram pacientemente conjuradas. Para desanuviar o ambiente suspicaz dos adeptos do novo regime tiveram enorme influência as pregações de um Júlio Maria . Repovoaram-se desde logo os conventos e mosteiros das antigas ordens religiosas. Em 1899 tomava parte o episcopado brasileiro no Concílio Latino Americano em Roma, cujas conclusões se traduziram na melhor organização das atividades pastorais. Consubstanciou-se esse programa no magnífico documento preparado pelos bispos do Sul do país, reunidos no Colégio Anchieta em 1915. A nova Pastoral Coletiva, pouco depois adotada pelo episcopado do Norte, vinha atualizar as celebres Constituições da Bahia, de 1719 .

Depois dessa pastoral, a história da Igreja no Brasil não registrou documento episcopal que tivesse no país tão grande repercussão, nem fosse mais oportuno que a carta pastoral de Dom Sebastião Leme da Silveira Cintra, novo arcebispo de Olinda e Recife em 1916. Foi um brado de pastor vigilante e ao mesmo tempo um admirável programa de ação. Focalizando especialmente a generalizada ignorância religiosa, traçava os caminhos da elevação intelectual para o Brasil Católico. Surgia um grande chefe para o movimento revitalizador da Fé Católica em nossa pátria.

A Dom Leme, depois cardeal arcebispo do Rio de Janeiro, se podem atribuir, entre outras iniciativas, todas elas ditadas pelo mais acendrado zêlo religioso, as três seguintes, do mais alto valor para a Igreja no seu tempo: o Pontifício Colégio Pio Brasileiro de Roma, a funda-

(10). - Op. cit., p. 159. 
ção de nossa primeira Universidade Católica na então Capital do país, a realização no Rio de Janeiro em 1939 do I Concílio Brasileiro. Sua eloquência, sua piedade, seu descortínio,.o impuseram largamente como lider religioso do país. O bom entendimento entre o poder civil e o poder eclesiástico, já anteriormente manifestado pela restauração da nunciatura em 1901, pela criação do cardinalato no Rio de Janeiro em 1905, materializou-se na Constituição de 1934 sob a forma expressa de uma colaboração para o bem comum.

Fomentou-se então a Ação Católica entre os leigos, enquanto as Congregações Marianas, também consideradas por Pio XII uma outra forma de ação católica, chegaram ao seu florescimento máximo, com cerca de meio milhão de inscritos. Espalharam-se pelo país os Círculos Operários. Em torno de Leonel Franca, o admirável filósofo e polemista da Companhia de Jesus, cristalizou-se ardente e numeroso grupo de pensadores cristãos, já conclamados anteriormente pelo desassombro de um Jakson de Figueiredo. Cresceram e multiplicaram-se as famílias religiosas de um e outro sexo. Criaram-se inúmeras obras de assistência, escolas, colégios e faculdades superiores. Prosperaram os noviciados e os seminários.

Beneditinos, carmelitas e franciscanos, recuperando a pujança de suas renovadas comunidades e dedicando-se ao cumprimento de suas respectivas regras e às finalidades de seus institutos, muito concorreram desde então para a expansão da espiritualidade católica e a renovação da vida religiosa no país. Além de suas atividades missionárias em longínquos rincões de nosso território, criaram os franciscanos em Petrópolis, com a Editora Vozes, um apreciável centro de irradiação do pensamento católico. Os beneditinos, consagrados tradicionalmente ao fomento do culto litúrgico, souberam congregar em torno de seus mosteiros um notável movimento de piedade entre leigos de boa formação intelectual, de que não poucos se sentiram atraidos pelo ideal monástico do Ora et labora.

Para citarmos apenas um dos admiráveis prelados, que, fora da capital do país, se distinguiram como pastores do rebanho de Cristo, não podendo alongar-nos nesta breve exposição, fixemo-nos na figura hierática e na atuação marcante de um Dom Duarte Leopoldo e Silva, de quem Dom Leme fora a princípio colaborador e depois íntimo amigo. Homem de Deus na plena significação do vocábulo, possuidor de excelente formação civil e eclesiástica e não menores qualidades de primoroso escritor e orador sacro, grangeou pela sua vigorosa personalidade o respeito e a admiração, não apenas dos fiéis, mas de todos os seus concidadãos em geral. Durante seu dilatado governo episcopal em São Paulo, como bispo (1907-1909), depois como seu primeiro arcebispo 
(1909-1938), pôde desenvolver, por isso mesmo, incomparável ação pastoral.

Graças à sua firme e religiosa direção, constituiu-se a nova arquidiocese numa circunscrição modelar da Igreja universal. Correspondendo à austeridade, cultura e zêlo de um numeroso clero secular e regular, arregimentou-se o laicato de ambos os sexos, em variadas associações religiosas, em favor das grandes causas inspiradas na mensagem do Evangelho: criou-e em São Paulo magnífica organização assistencial, logrou o culto sagrado verdadeiro esplendor e a doutrina religiosa e a influência da Igreja obtiveram no campo social extraordinário incremento. Sem falar nas obras materiais, como a construção da nova Catedral, do Seminário Central do Ipiranga, da Cúria Metropolitana, com seu bem organizado arquivo e precioso museu de arte sacra.

Com a encíclica Lacrimabili statu de São Pio X, do ano de 1912, documento que trata dos direitos das populações indígenas da América e da restauração das missões católicas em seu favor, começam a surgir no interior do país as prelasias apostólicas, hoje em número de quarenta, das quais onze organizaram já eficazmente a evangelização de nossos selvícolas. Aumentaram de então para cá assombrosamente os nossos bispados. Em princípios do ano corrente contava a Igreja no Brasil quatro cardeais, trinta e seis arcebispos e duzentos e quarenta bispos, a terceira hierarquia mais numerosa do mundo. Treze mil sacerdotes, entre seculares e regulares, compõem atualmente o clero no Brasil. O Congresso Eucarístico Internacional de 1955 no Rio de Janeiro, organizado pelo saudoso Cardeal Dom Jaime de Barros Câmara, foi a demonstração pública dessa vitalidade da Igreja entre nós. Nossa representação no Concílio Vaticano II esteve à altura do título que a Santa Sé já nos reconhece de maior nação católica do mundo.

A devoção à Mãe de Deus, pedra de toque do espírito católico e especial característica da religiosidade da "Terra de Santa Maria", preciosa herança, por isso mesmo, da Igreja no Brasil, encontrou no Santuário de Nossa Senhora da Conceição Aparecida sua mais notável manifestação na América. Elevado em 1893 a "Santuário episcopal", por Dom Lino Deodato Rodrigues de Carvalho, escoimadas as romarias populares de abusos e profanidades pela energia de Mons. Claro Monteiro do Amaral, foi entregue o templo da Senhora ao zelo dos filhos de Santo Afonso de Ligório, que até hoje ali desenvolvem com a maior eficácia o seu ministério sacerdotal e dali irradiam para todo o país magnífico apostolado.

De 1894 para cá, vem o Santuário de Aparecida se firmando como autêntica frágua de piedade cristã e de renovação religiosa pes- 
soal e coletiva. Calculam-se em três milhões de pessoas os que acodem todos os anos nestes últimos tempos à Basílica da Padroeira do Brasil. Tornou-se Aparecida o mais concorrido Santuário Católico Mariano do mundo. Em 1904, em solene concentração de bispos e fiéis, foi coroada oficialmente a imagem de Maria Imaculada, por decisão de São Pio X, e acabou por ser proclamada em 1930, por Pio XI, como padroeira da nação. A 15 de agosto de 1967, já na nova e grandiosa basílica em construção, se procedeu, com a presença do Presidente Costa e Silva, à outorga, feita ao Santuário pelo Papa Paulo VI, da "Rosa de Ouro". Essa edificação em andamento cada vez mais rápido, será, após a Basílica de São Pedro em Roma, o maior templo da Cristandade.

Em traços muito ligeiros, desprezando necessàriamente inúmeros aspectos da evolução religiosa do Brasil, desenvolvemos o tema que nos sugeriu o sesquicentenário da Independência: "a expansão da Igreja Católica no Brasil Independente". Devemos acrescentar agora que a impressão de auforia, que esta exposição poderia causar, já não corresponde infelizmente à realidade destes últimos anos de post-concílio. O que de mal produziu outrora o despotismo "esclarecido" do Marquês de Pombal parece reproduzir-se hoje, debaixo de uma feição ainda mais grave, por vir do interior da própria Igreja.

$O$ virus da heresia e da indisciplina, senão da descrença, vai-se infiltrando neste momento pelo organismo da Igreja: esvasiam-se os noviciados e os seminários, pululam as deserções entre as fileiras sagradas, estiolam as famílias religiosas, o ensino ministrado no livros, nas cátedras e nos púlpitos semeia por vezes a dúvida ou estadeia o escândalo. As preocupações de ordem sobrenatural desaparecem em muitos setores, para dar lugar a programas de reforma social e política. Multiplicam-se, por isso mesmo, os choques com o poder civil, que detem naturalmente a prioridade de encaminhar a solução de tais problemas de ordem terrena e temporal...

É cedo para definir adequadamente o doloroso fenômeno, que se passa no seio da Igreja, não apenas no Brasil, mas em todo o mundo, como tantas vezes tem denunciado o Santo Padre, o Papa. Seria acaso o contágio do marxismo triunfante a difundir-se no pensamento e nas organizações eclesiásticas? Ou será o recrudescimento daquela heresia total, que se chamou o "modernismo", condenado em princípios deste século por São Pio X? Juntando os dois aspectos do fenômeno, talvez pudéssemos falar em um neomodernismo-progressista...

Confesso que nunca imaginara anos passados assistir em dias de minha vida a espetáculo tão contristador. Na própria história da Igre- 
ja, todavia, encontro razões sobejas para não descrer da vitória final da ortodoxia e da santidade. Apliquemos além do mais objetivamente ao caso uma feliz observação da atualidade política americana: a existência de uma grande maioria silenciosa. Não! Não é a Igreja, na sua totalidade e muito menos ainda na sua essência, que nos está dando este espetáculo. Ela continua o que sempre foi: una, sancta, catholica et apostólica.

São grupos bem organizados em situações estratégicas, audazes, ativos e ruidosos, que se vão isolando à medida que se desmascaram $\mathrm{e}$ que irão esfacelar-se por si mesmos, desde que não permanecem na verdade... Tal como o anjo das trevas que in veritate non stetit (Jn., VIII, 44). Essa verdade de que o próprio Cristo é fiador e que deverá chegar intacta ao final dos tempos; et portae Inferi non praevalebunt (Mt., XVI, 18)!

"O que nos parece um por de sol - repetiremos com Dom Antônio de Macedo Costa, em plena "Questão religiosa" — é uma aurora! A cruz nua do Calvário está anunciando uma ressurreição... Ruja a tormenta embora, cerre-se a noite sobre este triste mundo que parece voltar ao paganismo: os farois estão acesos! A costa toda iluminada!” (11).

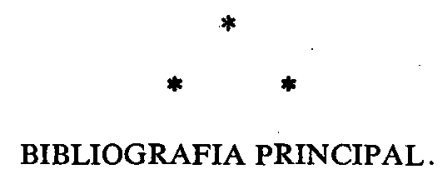

Almeida (Cônego Luis Castanho de), O sacerdote Diogo Antônio Feijó, Petrópolis, 1951 .

— Dom Luis, Petrópolis, 1956.

— São Paulo. Filho da Igreja, Petrópolis, 1957.

Arquivo Nacional, Cairú, Rio de Janeiro, 1958.

Azeredo (Carlos Magalhães de), $O$ reconhecimento da Independência $e$ do Império do Brasil pela Santa Sé, Roma, 1932.

Barbosa (Padre Manuel), A Igreja no Brasil, Rio de Janeiro; 1945.

Camargo (Monsenhor Paulo Florêncio da Silveira), História eclesiástica do Brasil, Petrópolis, 1955.

(11). - Dom A. de Almeida Lustosa, Dom Antônio de Macedo Costa, Rio de Janeiro, 1939, p. 301. 
- Dom Duarte Leopoldo e Silva, em Revista do Instituto Histórico e Geográfico de São Paulo. Vol. LXV. (1968), 22-43 e vol. LXVI, (1969), 46-78;

— A Igreja na História de São Paulo. 7 vols.. São Paulo. 1952-1953.

Centro Dom Vital, Jackson de Figueiredo - In Memoriam, Rio de Janeiro, 1929.

CERIS, Anuário Católico do Brasil. Rio de Janeiro. 1965.

CNBB, Diretório Litúrgico, Rio de Janeiro, 1972.

Correia S. D. B. (Dom Aquino), Bispos do Brasil, Rio de Janeiro, 1939.

- Dom José Antônio dos Reis, Rio de Janeiro, 1954.

Costa (Francisco de Maceo), Lutas e vitórias, Bahia, 1916.

D'Elboux, S. J. (Luis Gonzaga da Silveira), O Padre Leonel Franca S. J., Rio de Janeiro, 1953; - Crise religiosa, Rio de Janeiro, 1969.

Galanti S. J. (P. Rafael M.), História do Brasil, 5 vols., 2a. ed., São Paulo, 1911-1913.

Guimarães (Alberto Prado), Notas biográficas sobre Dom José de Afonseca e Silva, São Paulo, 1963;

— Traços biográficos de D. Duarte L. e Silva, em Diário Popular, São Paulo, 4-IV-1967.

Isnard O. S. B. (Dom Clemente), O Cardeal Leme e a promoção do laicato católico brasileiro, em Revista Eclesiástica Brasileira (REB), XXVI (dezembro de 1967), 817-836.

Lacombe (Américo Jacobina), Problemas religiosos no Brasil Império (resumo de duas palestras), Rio de Janeiro, 1971 .

Lacroix S. C. J. (Pascoal), O mais urgente problema do Brasil; o problema sacerdotal e a sua solução, Petrópolis, 1936.

Lustosa S. D. B. (Dom Antônio de Almeida), Dom Antônio de Macedo Costa, Rio de Janeiro, 1939.

Madureira S. J. (Padre José Manuel de), ...A A Companhia de Jesus..., 2 vols. Rio de Janeiro, 1927-1929.

Moraes (Eugênio Vilhena de), $O$ patriotismo e o clero no Brasil, Rio de Janeiro, 1929;

- O Gabinete Caxias e a anistia uos bispos na Questão Religiosa, Rio de Janeiro, 1930 .

Olivola O. M. Cap. (Frei Félix de), Um grande brasileiró - ... Dom Vital, 4a. ed., Recife, 1967.

Pacca (Bartolomeo), Notizie sul Portogallo, Velletri, 1835.

Palazzolo O. M. Cap. (Frei Jacinto de), Crônica dos Capuchinhos no Rio de Janeiro, Petrópolis, 1966. 
Pimenta (Dom Silvério Gomes), Vida de Dom Antônio Ferreira Viçoso, Mariana, 1876.

Primeiro O. M. Cap. (Frei Fidelis de), Capuchinhos em Terras de Santa Cruz, São Paulo, 1940.

Revista do Instituto Histórico e Geográfico Brasileiro, sobretudo "Tomos especiais" (Documentos do Arquivo Histórico Ultramarino sobre São Paulo), Rio de Janeiro, 13 vols. Rio de Janeiro, 1956-1959.

Rodrigues (Júlio), Dom Duarte Leopoldo e Silva - Esboço biográfico (1894-1929), São Paulo, 1929.

Röwer O. F. M. (Frei Basílio), A Ordem Franciscana no Brasil, 2a. edição, Petrópolis, 1957;

- História da província franciscana da Imaculada Conceição no Brasil, Petrópolis, 1951.

- O Convento de Santo Antônio do Rio de Janeiro, Petrópolis, 1945.

Sant'Anna O. M. Cap. (Dom Frei Luis de), Oração Fúnebre de Dom Duarte Leopoldo e Silva, São Paulo, (1938).

Santo Rosário O. C. D. (Ir. Maria Regina do), O Cardeal Leme (1882-1942), Rio de Janeiro, 1962.

Seixas (Dom Romualdo Antônio de), (Marquês de Santa Cruz), Coleção das Obras, 5 volumes, Pernambuco, 1939-1858.

Serrano (Jônatas), Júlio Maria, 2a. edição. Rio de Janeiro, sem data.

Silva (Dom Duarte Leopoldo e Silva), $O$ clero e a independência, 2a. edição, São Paulo, 1972.

Talassi (Padre Luis), A doutrina do Padre Feijó, São Paulo, 1954.

Trindade (Cônego Raimundo), Arquidiocese de Mariana, 2 volumes, 2a. edìção, Belo Horizonte, 1953-1955.

- Breve notícia dos Seminários de Mariana, São Paulo, 1953.

Vários autores, Província franciscana de Santo Antônio do“- Brasil, (1657-1957), $1^{9}$ volume, Recife (1957).

Viotti S. J. (Pe. Hélio Abranches), Pio $I X$ e o Brasil, separata da REB, XXIII (setembro de 1963), pp. 658-680;

- No cinquentenário de Monsenhor Claro Monteiro do Amaral, separata da Revista do Arquivo Municipal (São Paulo), vol. CXLI, 1951, 4153. 